\title{
19. Yüzyılda Osmanlı Topraklarında Eğitimci Bir Misyoner: Wilson Amos Farnsworth'un Kapadokya Faaliyetleri ${ }^{1}$
}

\author{
DOI: 10.26466/opus.560699
}

\section{Ercan Kaçmaz - Büşra Figenkaplan**}

*Dr. Öğretim Üyesi Nevşehir Hacı Bektaş Veli Üninersitesi, Eğitim Fakültesi / Nevşehir /Türkiye E-Posta: ercankacmaz@gmail.com

ORCID: 0000-0001-8304-6482

** Uzman Araş., Nevşehir Hacı Bektaş Veli Üniversitesi, Sosyal Bilimler Enst. Nevşehir/Türkiye E-Posta: bsrafgnkpln.34@gmail.com

ORCID: $\underline{0000-0001-9418-2404}$ Öz

19. yüzyıl ve 20. yüzyıl Osmanl Devleti'nin değişime açık olduğu bir dönemdir. Zikredilen dönemlerde hükümet, devlet idaresinin yanında, sivil ve askeri okullar, ticaret odalarl gibi sivil organizasyonları, tarikatları ve nihayet hâlâ dini eğitimin en iyi temsilcileri olan medreseleri kontrolü altına alıp; kendi zihniyeti ve ideolojisi doğrultusunda şekillendirmek sureti ile gücünü büyük bir oranda arttırmak istiyordu. Fakat hükümetin gerçekleştirmek istediği bu reformlar; savaş, siyasi istikrarsızlık ve ekonomik dalgalanmalar nedeniyle büyük ölçüde altyapıdan yoksundu ve durum genel olarak stabil değildi. 19. ve 20. yüzyılda, Osmanlı devlet yapısı içerisinde hemen her gün yeni kanunlar çıkıyor, birine alısmadan öteki devreye sokuluyordu. Bir yıldan fazla görevde kalan eğitim bakanı neredeyse yok gibiydi. Bu durum bile, dönemin ne kadar çalkantıll, dalgalı ve istikrarsız olduğunu göstermesi açışından oldukça çarpıcıdır. Sistem değişince kurumların değişmesi de kaçınılmazdı. Batı'da modernleşme, radikal sistem değişiklikleri olmadan gerçekleştiği için eski sistemin kurumları kolaylıkla ıslah edilebilmiştir. Osmanlı'nın ise modernleşmesi geleneğe karşı başlamıştır. Bu durum Osmanlı toprakların misyoner eğitimcilerin faaliyetlerini kolayca gerçekleştirebilecekleri bir alan haline getirmiştir. Bunlardan birisi de Wilson Amos Farnsworth olmuştur. Farnsworth, Osmanlı Devleti'nin bu durumunu firsata çevirerek, Amerikan Board Teşkilatı aracılığı ile dünyanın bir ucundan diğer ucu olan Kapadokya bölgesine misyonerlik faaliyetlerini gerçekleştirmek adına gelmiştir. Bu çalışma, 19. yüzyıl döneminde eğitim anlamında oluşan boşlukların yabancı misyonerler tarafından nasıl doldurulmaya çalışıldığıına dair bir tablo çizecektir.

Anahtar Kelimeler: Osmanl, 19. Yüzyıl, Ĕ̆itim, Modernleşme, Misyoner.

\footnotetext{
${ }^{1}$ Bu makale 30 Ocak - 02 Şubat 2019 tarihleri arasında Nevşehir Hacı Bektaş Veli Üniversitesi ev sahipliğinde düzenlenen 2.Uluslararası Sosyal Bilimleri Kongresi'nde (USBIK 2019) sözlü bildiri olarak sunulmuştur.
} 


\title{
An Educator on a Mission in Ottoman Lands in the 19th Century: Wilson Amos Farnsworth's Cappadocia Activities
}

\begin{abstract}
19th century and 20th century is a period when the Ottoman state was open to change. In the mentioned periods, the government wanted to increase the power of the state by the state administration as well as the civil organizations such as civilian and military schools, chambers of commerce, sects, and finally by taking control of madrasahs, which are the best representatives of religious education, and by shaping them in line with their own mentality and ideology. However, these reforms, which the government wanted to carry out, lacked much infrastructure due to war, political instability and economic fluctuations, and the situation was not stable. In the 19th and 20th centuries, almost every day, new laws emerged within the Ottoman state structure, and one was engaged in the other without getting used to. The minister of education, who spent more than a year in office, seemed almost absent. Even this situation is quite striking to show how volatile, fluctuating and unstable the period is. When the system changed, it was inevitable for the institutions to change. In the West, because the modernization took place without radical system changes, the institutions of the old system could easily be reformed. Ottoman modernization began against tradition. This situation has made the Ottoman lands an area where missionary educators can easily carry out their activities. One of them was Wilson Amos Farnsworth. Farnsworth turned this chance into an opportunity by the American Board to carry out its activities from one end of the world to the other end of the Cappadocia region. This study will focus on of how the gaps in the educational sense of the period are tried to be filled by foreign missionaries.
\end{abstract}

Keywords: Ottoman, $19^{\text {th }}$ Century, Education, Modernization, Missionary 


\section{Giriş}

İlk olarak misyonerlik faaliyetlerini anlatmadan batıllaş̧ma ve modernleşme' nin ne anlama geldiğinin ortaya konması bu çalışmanın daha iyi anlaşılmasını sağlayacaktır. $\mathrm{Bu}$ hususta modernleşme bir nevi çağdaşlaşma; aklın, ilmin, sezginin rehberliğinde, tabiat ve cemiyet kanunlarını keşfederek; mal, hizmet, fikir üretmek ve böylece maddi refah gücünü ve manevi gücü yakalamaktır. Osmanlı Devleti çağına göre kendi ilmi ve teknolojisi ile coğrafyasına, kültürüne, moral dünyasına hâkimdir ve diğer medeniyetlerle olan temasını sürdürmüştür (Kodaman, 2005, s.150).

19. yüzyılda bütün modernleşen ve modernleşmekte olan ülkelerde olduğu gibi Osmanlı Devleti'ndeki siyasal gelişmelerle eğitim alanındaki gelişmeler iç içe geçmiş bir şekilde karşımıza çıkmaktadır. Siyasal hayatta meydana gelen gelişmeler eğitimin içerisine yansımakta gecikmemiştir. Akabinde eğitim kurumları sadece sosyalleşme, bilgi ve beceri kazandırma yerleri değil, aynı zamanda ve etkin bir biçimde resmi ideolojilerin aktarıldıkları kurumlardır. Osmanlı Devleti'nin modernleşmesi bir bakıma eğitim ile iç içe geçmiş bir süreç olarak yaşanmıştır (Alkan, 2008, s.9-10).

19. yüzyılda Osmanlı Devleti'nin kendi içerisinde değişim ve dönüşüme girmesiyle beraber sistemin belli halkalarında zayıflamalar meydana gelmiştir. Özellikle eğitim alanındaki yaşanan sarsıntılar misyonerlerin dikkatinden kaçmamıştır. Bunu fırsat bilerek eğitim üzerinden Osmanlı toplumunda ve devlet yapısı içerisinde nüfuz edinmeye çalışmışlardır. Osmanlı Devleti'nin bu durumunu fark eden Amerikan Board Teşkilatı bu boşluğu doldurmak için girişimlerde bulunmuşlardır. $\mathrm{Bu}$ çalışma, devlet yapısında değişimlerin yaşanmasıyla ve ortaya çıkan modernleşme süreciyle beraber misyonerlik faaliyetlerinin Kapadokya ayağının getirdiği değişimler ve etkileri üzerinde duracaktır.

\section{Yüzyıl Osmanlı Dünyasında Modernleşme ve Eğitime Kısa Bir Bakış}

Osmanlı Devleti yüzyıllar boyunca Doğu medeniyetinin en büyük temsilcisi konumunda idi. Osmanlı, Tanzimat Fermanı ile beraber belir- 
gin bir biçimde Batı medeniyeti dairesine yakınlaşmaya başlamıştır. 17. yüzyıla kadar ilim ve teknolojide ileri seviyede olan devlet, güç kaybı içerisine girmiş; Osmanlı'nın devlet yapısı içerisinde Batı kültür ve medeniyeti bilhassa 19. yüzyılda kendini hayatın her alanında hissettirmiştir. 19. yüzyıl, Osmanlı'da yenileşme hareketinin en yoğun olduğu dönemdir (Karabulut, 2016, s.50).

Batılılaşma modernleşme sürecini tanımlayan bir kavramdır. Bilhassa bu süreç İstanbul da ön plana çıkmıştır (Artıkoğlu, 2007, s. 48). Osmanlıları batılılaşmaya teşvik eden esas ise Avrupa'nın 18. yüzyıldan itibaren Osmanlı Devleti üzerinde devamlı bir şekilde artmaya başlayan siyasi, askeri ve iktisadi baskısıdır. Bu duruma binaen baskıları hafifletmek adına Avrupa devletlerinin yeniliklerini takip etmek ve fikir alanındaki müesseselerini benimsemekten başka çare yoktu. Ancak bu Osmanlı için kolay bir durum değildi. Sebebi ise 'şarkı' temsil eden Osmanlı ile 'garbı' temsil eden Avrupa arasında moral olarak uçurumun olmasıdır. Uçuruma neden olan unsur, medeniyet anlayışından ileri gelmektedir. Osmanlı Devleti için garp medeniyeti, Hıristiyanların bir eseri konumundadır; yalnızca Hıristiyan devletlerinin veya cemiyetlerinin bünyesine uygundur. Müslüman bir cemiyetin bu medeniyete intisabı kolay değildir. Bu anlayışa rağmen 19. yüzyılın ilk yarısından itibaren, batılılaşma fikri Osmanlı'ya sızmıştır. Beraberinde ise Osmanlı'da batılılaşma hareketinin başladığ görülmektedir (Karal, 2011, s.328-329).

Diğer taraftan Osmanlı Devleti'nin, bir medeniyetin temsilcisi olarak kendi medeniyeti dışındaki başka bir medeniyetin doğduğu Avrupa'ya olan bakış açısını süreç içerisinde değiştirmiş olması kültür değişimi mahiyetinde ele alınabilir (Karagöz, 1995, s.176). Bu doğrultuda bakıldığ1 zaman Osmanlı Devleti'ndeki modernleşme sürecinin Batı'daki modernleşme süreci ile paralellik göstermediği görülmektedir. Nedeni ise Batı'da modernleşme sürecinde, toplum ile devletin zaman zaman birbirinden bağımsız bir şekilde hareket etmiş olmalarıdır. Batı toplumlarındaki yenileşme hareketi toplumun bilinçlenmesi ile oluşan bir süreçtir. Batı'nın yaşadığı bu durum ilk olarak aydınlanma daha sonrasında da modernleşme olarak adlandırılır. Osmanlı'daki durum Batı'dakinden farklılık göstermektedir. Osmanlı ile Batı'nın toplum yapısı birbirinden farklıdır. Osmanlı Devleti'ndeki modernleşmeyi anlayabilmek için ilk olarak toplum yapısını anlamak gerekmektedir. Halk, Osmanlı 
Devleti'nde, Müslim veya gayrimüslim ayrımı yapılmaksızın, yönetici sinıf ve reaya olarak ikiye ayrılmaktadır. Osmanlı'nın en belirgin yanı bürokratik bir devlet olmasıdır. Bu durum, merkez olarak kabul edilen yönetici sınıf ile çevre olarak adlandırılan halk arasında bir kopukluk yaratmaktadır (Fidan, Şahin ve Çelik, 2011, s.114-115).

19. yüzyılda Osmanlı Devleti'nde görülmekte olan yenileşme yani modernleşme çabasının köklerinde, anlaşıldığı üzere merkezileşme dürtüsü yatmaktadır. Osmanlı'nın modernleşmesi, üç koşula bağlı olarak gelişmiştir. İlk husus zikrettiğimiz gibi merkezileşme dürtüsüdür. Bu durum siyasi yapıyı yeniden şekillendirmiştir. Siyasi zümre ile sosyal gruplar arasında var olan ikilemi derinleştirmiştir. Ayrıca devlet-toplum ilişkisi birbirinden ayrılmıştır. İkinci koşul, Avrupalı güçlerin gitgide artan siyasi nüfuzudur. Bu da devleti, Osmanlı siyasi kültürüne ve geleneksel toplum yapısına yabancı olan yeni kurum ve uygulamaları benimsetmek zorunda bırakmıştır. Oluşturulan yeni kurumlar, kültürel olarak olumsuz etki yaratmıştır. Her iki koşulun bir nevi sonucu olan üçüncü koşul ise modernleşmenin ideolojik boyutunu oluşturmaktadır. Devletin ileri gelenleri bu üç koşulu yönlendirme gücünü ellerinde tutuyorlard1 (Karpat, 2014, s.79-80).

Osmanlı Devleti'nin klasik sistemi, bakıldığı zaman bazı keskin dönemeçlerine rağmen, Tanzimat'ı hazırlamış olan II. Mahmud dönemindeki 'devrimci dönüşüm'e kadar etkisini sürdürmüştür (Emecen, 2016, s. 389). Bu bağlamda modernleşme yolundaki ilk adım, III. Selim zamanında atılmıştır. Bu da III. Selim'in kendisine sadık bir ordu kurma çabasından ileri gelmektedir (Karpat, 2014, s.80).

18. yüzyılda III. Selim ile başlayıp 19. yüzyılda II. Mahmud'la yaygınlaşarak devam eden reformlar, hem halkın hem de medreselerin etki ve yetkilerini kısıtlamıştır (Sarıkaya, 1997, s.75-76). Tanzimat'a kadar Avrupa'dan özellikle askeri teşkilat ve teknik alınmıştır. Fakat Tanzimat'tan itibaren hukukta ve devlet nizamı teşkilatında Batı görüşü benimsenmiştir (Cebeci, 2009, s.53-54). Tanzimat öncesinde Osmanlı'da İslam Hukuku hâkimdi. Tanzimat'la beraber Avrupa'dan alınan kanunlar da uygulanmaya başlamıştır (Figenkaplan, 2018, s.25). Bu gelişmelere rağmen medreseler; hâkim, hukukçu, imam, müftü, tabip, matematikçi ayrıca kısmen de olsa yüksek dereceli devlet memuru ve bürokrat 
yetiştirmede hâlâ önemli bir kurum olarak önemini 19. yüzyılın ilk yarısına kadar sürdürmüştür (Sarıkaya, 1997, s.76).

Osmanlı Devleti'nin 19. yüzyıldaki eğitim anlayışına bakmadan önce Osmanlı'da aile içi çocuk eğitimi konusuna değinmek yerinde olacaktır. Osmanlı'da eğitim ilk olarak anne tarafından çocuğa ilk yaşlarında verilmekteydi. Belli bir öneme sahip olan ailelerde durum daha farklıydı; öncelikli olarak sütnine daha sonrada kâhya kadın bu eğitimi veren kişiler arasında yer almaktadır. Fakat her ne olursa olsun iki durum göz önüne alındığında ilk eğitimi veren kişi yine anne olmuştur (Figenkaplan, 2018, s. 17). 19. yüzyıl seyyahlarından biri olan Julia Pardoe, Osmanlı'da eğitim konusunda annenin önemini şu şekilde tanımlamaktadır: "Türklerin temel vasıflarının en güzellerinden bir tanesi de kendi varlık sebepleri olan kişiye gösterdikleri ihtimam ve hürmettir. Anne yol gösteren bilgedir. Ona danışılır, ona dert yanılır, onun söyledikleri büyük bir saygıyla dinlenir, işler onun kararına bırakılır, son saatine kadar el üstünde tutulur, vefatından sonra da büyük bir sevgi ve hasretle anılır." Pardoe, annenin temel eğitimin verilmesindeki önemine dikkat çekmektedir (Pardoe, 1837, s. 378).

18. yüzyılın sonlarına gelinceye kadar dönemin en yaygın eğitim kurumları ise "sıbyan mektepleri" ile "medreseler" idi (Akyüz, 2011, s. 12). Osmanlı Devleti'nde 19. yüzyıla kadar mektep ve medreseden oluşan öğretim kurumları, "şeyhülislamlık" makamına bağlıydı (Duran, 2017, s. 64). Şeyhülislamlık yenileşme dönemine kadar eğitim ve öğretim alanında en yüksek makam konumundadır. Fakat şeyhülislamlık bir tür eğitim bakanlığı niteliğini taşımamaktadır. Şeyhülislam, ulemanın başıdır. Ayrıca ülkenin her köşesine dağılmış olan çeşitli yapıdaki medreselerin kendi vakıflarına göre ve çoğunlukla sülaleye, aileye veya mahalli özelliklere göre elden ele geçmekte olan tedris kürsülerinde görev alan taşra müderrisleri üzerinde de fazlaca yönetsel bir yetkisi bulunmamaktadır. Taşra müderrisleri daha çok yerel ulema başkanı sayılmakta olan müftülerin denetimindedir (Soydan ve Tüncel, 2013, s.113).

Osmanlı Devleti'nin eğitim alanındaki modernleşmesine baktığımız zaman, 1700'lerin sonundan başlayarak devletin sona ermesine kadar devam ettiği görülmektedir. Osmanlı'da, batılılaşma ve yenilik hareketleri çoğunlukla askeri, siyasi, idari ve az da olsa sosyal sahada yapılmıştır. Bu, padişah ve sadrazamın doğrudan etkisinin olduğu ku- 
rumlarda başlamış ve devam etmiştir (Karataş, 2003, s.232). 1839'da Tanzimat Fermanı'nın ilanı ile yeni bir dönem başlamıştır. Fermanın ilan edilmesi modernleşme yolunda oldukça önemli bir adım olmuştur. Düzenin devamlılığını sağlamak adına kapsamlı bir yeniden yapılanma süreci başlamıştır (Bozaslan ve Çokoğulları, 2015, s.313).

19. ve 20. yüzyıl dönemlerinde hükümet devlet idaresinin yanında, sivil ve askeri okulları, ticaret odaları gibi sivil organizasyonları, tarikatlar ve nihayet hâlâ dini eğitimin en iyi temsilcileri olan medreseleri kontrolü altına alıp, kendi zihniyeti ve ideolojisi doğrultusunda şekillendirmek sureti ile gücünü büyük bir oranda arttırmak istiyordu. Fakat hükümetin gerçekleştirmek istediği bu reformlar, savaş, siyasi istikrarsızlık ve ekonomik dalgalanmalar nedeniyle büyük ölçüde altyapıdan yoksundu ve durum stabil değildi. 19. ve 20. yüzyılda Osmanlı devlet yapısı içerisinde hemen her gün yeni kanunlar çıkıyor, birine alışılmadan öteki devreye sokuluyordu. Bir yıldan fazla görevde kalan eğitim bakanı neredeyse yok gibiydi. Bu durum, dönemin ne kadar çalkantılı, dalgalı ve istikrarsız olduğunu göstermesi açışından oldukça çarpıcıdır (Sarıkaya, 1997, s.75).

Sistem değişince kurumların değişmesi de kaçınılmazdı. Batı'da modernleşme, radikal sistem değişiklikleri olmadan gerçekleştiği için eski sistemin kurumları kolaylıkla ılah edilebilmiştir. Osmanlı' nın modernleşmesi ise geleneğe karşı başlamıştır (Sarıkaya, 1997, s.200). Bu durum, Osmanlı topraklarını misyoner eğitimcilerin faaliyetlerini kolayca gerçekleştirebilecekleri bir alan haline getirmiştir. Bu misyonerlerden birisi de Wilson Amos Farnsworth olmuştur. Farnsworth, Osmanlı Devleti'nin bu durumunu fırsata çevirmek isteyen Amerikan Board Teşkilatı aracılığı ile dünyanın bir ucundan bir diğer ucu olan Kapadokya bölgesine misyonerlik faaliyetlerini gerçekleştirmek adına gelmiştir.

\section{Amerikan Board ve Türkiye'de Erkek Misyoner Eğitimciler}

Amerikalı Protestan misyonerlerin Osmanlı topraklarına ilk ayak basmaları, teşkilatın kurulduğu tarihten çok uzun bir zaman geçmeden olmuştur. Bu misyoner teşkilat Amerika'nın Massachusetts eyaletinde Williams Kolej'i öğrencileri tarafından 1810 yılında organize edilmiş 
ancak yasal olarak 1812 yılında faaliyetlerine başlamıştır (Missionary Research Library Archives, 1878-1958, 03.03.2019). Protestanlığın yayılması için kısaca ABCFM olarak anılan American Board of Commissioners for Foreign Missions ${ }^{2}$ adı altında bir örgütlenme ile kurulmuştur. $\mathrm{Bu}$ teşkilatın amacı bütün Amerika üzerinde ve dünyada Protestanlığ 1 yaygınlaştırmak olmuştur (Richter, 1910, s.73).

$\mathrm{Bu}$ teşkilata bağlı olan misyonerler dini bilgilerin yanı sıra bulundukları yerlerin sosyolojik ve kültürel durumunu araştıran, tarihini ve siyasi yapısım bilen veya inceleyip öğrenebilecek kapasitede olan kişilerdir. Kısaca, bir misyonere nerede görev verilmişse oraya gider toplumun genel özellikleri hakkında bilgi toplar ve ardından bağlı olduğu teşkilata ve devletine bilgi verir (Döşkaya, 2018, s.84-119).

$\mathrm{Bu}$ örgütlenmenin, Evanjelik (dini) yaklaşımının yanı sıra üzerinde önemle durduğu iki temel unsur daha dikkat çekmektedir; bunlardan birincisi eğitim, ikincisi ise sağlık olmuştur. Hıristiyan olmayan toplumlara ulaşarak onları kendi din anlayışları doğrultusunda yönlendirmek üzere harekete geçen misyonerler, dini yapıyı değiştirmek için eğitim alanını ön plana çıkarmışlardır. Ayrıca Osmanlı Türkiye'sinde hâlâ etkisini görebildiğimiz kolejler kurmuşlar ve eğitim faaliyetlerinde bulunmuşlardır. ${ }^{3}$

Amerikan Board Teşkilatı, zamanının en kapsamlı ve en yaygın ağa sahip örgütlenmesidir. Teşkilatın amaçları doğrultusunda Osmanlı topraklarına ilk gelen iki erkek Amerikalı misyoner Levy Parsons ve Plinky Fisk olmuştur. Bu topraklarda bazı keşif çalışmalarında bulunmak için 1818 yılında atamaları yapılmış ve 1820 yılında ise İzmir'e ayak basarak görevlerine başlamışlardır (Anderson, 1872, s.10-11). Bu misyonerlerin ardından William Goodell ve Isaac Bird adlı misyonerler 1823 yılında eşleri ile birlikte görevlerine başlamışlardır. Bu misyonerler çok geçmeden yaklaşık 4 yıl gibi kısa bir zaman içerisinde yani 1827 yılında ülkede 13 tane okul açmışlar ve bu okullarda 100'ü kız öğrenci olmak üzere yaklaşık 600 öğrenciye eğitim vermişlerdir (Strong, 1910, s.83).

\footnotetext{
${ }^{2}$ Bu çalışmada Amerikan Board olarak kullanılacaktır.

${ }^{3}$ Osmanlı Türkiyesinde kurulan belli başlı kolejler şunlardır: Robert Kolej (Robert College), istanbul Amerikan Kız Koleji (American College for Girls daha sonra Constantinople Woman's College), Merkezi Türkiye Koleji (Central Turkey College), Fırat Koleji (Euphrates College), Anadolu Koleji (Anatolia College), Merkezi Türkiye Kız Koleji (Central Turkey College for Girls), Tarsus Amerikan Koleji (Tarsus American College).
} 
Yine yaklaşık 4 yıl sonra 1831 yılında William Goodell uzun soluklu faaliyetlerini gerçekleştirmek için aktif çalışmalarına başlamıştır.

Goodell'i izleyen Harrison Gray Otis Dwight ve William Gottlieb Schauffler adlı erkek misyonerler eğitim faaliyetlerini çok hızlı bir şekilde ilerletmişlerdir (Richter, 1910, s. 107). Misyonerlik çalışmaları için görevlendirilen kişiler arasında H.G.O. Dwight ve Eli Smith adlı iki misyoner ülkenin birçok bölgesini karış karış gezmişler ve bulundukları yerleri anlatan mektuplar yazmışlardır. Yukarıda adı geçen önemli misyonerlere ek olarak Cyrus Hamlin, George Washburn ve Frank Caleb Gates gibi kişileri de sayabiliriz. Amerikan Board Teşkilatı'nın 1900'lü yıllarda ulaştığı okul sayısı 500'e yaklaşacak; açtıkları okullarda ise yaklaşık yirmi altı bin öğrenci eğitim alacak hale gelecektir (Greene, 1916, s. 108). Bu çalışma daha çok ve genel olarak Wilson Amos Farnsworth'un Kapadokya bölgesindeki 1854 ile 1904 yılları arasında gerçekleştirdiği misyoner faaliyetlerini kapsayacaktır.

Amerikan Board Teşkilatı tarafından verilen ilkokul eğitimi daha çok karma eğitim olarak yürütülmüş ama lise eğitimine gelindiğinde genelde kızlar ve erkekler ayrı eğitim alır hale gelmişlerdir. Ancak ilgi çeken bir konu şudur ki yapılan eğitim faaliyetlerinde kızların eğitimi her zaman önem arz etmiş; hatta bazı yerlerde erkeklerden daha fazla ön plana çıkartılmıştır. Kızların eğitimi, Farnsworth için de büyük önem taşıdığından, kendisi de kız eğitimine yeterli titizliği göstererek ilk olarak kız lisesinin açılmasını arzu etmiştir. Okulların birçoğunun yatılı olması bu misyonerlerin işini kolaylaştırmış ve öğrencileri etkileme konusunda daha başarılı olmuşlardır.

\section{Wilson Amos Farnsworth'un Kapadokya'daki Eğitim Faaliyetleri}

Wilson Amos Farnsworth ve Jasper Newton Ball doğrudan Amerikan Board'un görevlendirmesiyle, Kapadokya bölgesini kapsayan bir misyoner istasyonu kurmak üzere gönderilmişlerdir. Her iki misyoner de eşleri ile beraber bu bölgede bulunmuşlardır (Farnsworth, 2018, s.36). Wilson Amos, eşi Carolin Farnsworth'la Amerikan Board misyonerlerinin Osmanlı ülkesindeki faaliyetlerine katkıda bulunmak için dördüncü kuşak olarak 1853 yılında Osmanlı topraklarına ayak basmıştır. Bu çift 1854 yılında Kayseri bölgesine gelmiştir. Kayseri'nin üzerinde du- 
rulması gereken bir yerleşim yeri olduğunu vurgulayan Amerikan Board'un 1854 yılında kurmuş olduğu Kayseri İstasyonu'ndaki ilk misyonerler olarak çalışmaya başlamışlardır. Dördü Amerikalı misyoner, üçü de yerli yardımcı olacak şekilde, toplam yedi kişi bölgedeki misyonerlik çalışmalarına başlamışlardır. Fakat ön plana çıkan kişi ise Wilson Amos Farnsworth olmuştur (Demir, 2008, s.17-18).

Misyonerler bölgeye geldiklerinde doğrudan faaliyetlerine başlamamışlardır. İlk olarak halkı tanıyabilmek ve onların güvenini kazanmak adına önemli bir unsur olan dil eğitimi almışlardır. Bu kapsamda Wilson Amos ve eşi 10 ay kadar Merzifon'a dil eğitimi almak için gitmişlerdir (Farnsworth, 2018, s.57). Türkçe öğrenerek ve Türk gelenek göreneklerine de hâkim olmuşlardır. Wilson Amos Farnsworth misyonerlik faaliyetlerini daha rahat gerçekleştirebilmesi adına bir zemin oluşturmuştur. İki önemli politika izlenmiştir; bunun ilkinde sağlık ikincisinde ise eğitim yer almaktadır. Bilhassa bu politikalar azınlıklıklara yönelik uygulanmıştır.

Misyonerlerin ilk olarak Osmanlı Devleti'ndeki eğitim faaliyetleri, dini alandaki çalışmalara destek olmak maksadı ile başlamıştır (Demir, 2012, s.1407). Wilson Amos, Kayseri'nin nüfusu ile ilgi gözlemlerde bulunarak 75 bin civarında kişi olduğunu belirtmektedir. Ayrıca nüfusun 25 bin kadarını ise Hıristiyanların oluşturduğunu kaydetmiştir. Wilson Amos yazmış olduğu notlarında var olan gayrimüslim tebaaya ilişkin "olağanüstü bir enerji ve müteşebbislik yeteneğine ve de eğitime çok büyük ilgi duyduklarının" notunu da düşmüştür (Farnsworth, 2018, s.43).

Wilson, Kayseri'ye vardıktan sonra ilk önemli iş olarak bir cemaat oluşturma girişimlerinde bulunmuş; böylece 2 Temmuz 1854 yılında, dört erkek ve dört kadından oluşan bir cemaat kurulmuştur. Kurulan cemaatin ilk üyelerinden birisi Kayseri tarihinde önemli yer edinen 18 yaşındaki Kerope Yakubyan'dır. Kerope Yakubyan 12 yıl sonra Protestan kilisesinin ve cemaatinin en etkin dini önderi olmuştur. Bunların ardından Amos, yörede hiç dış istasyon olmamasından dolayı keşif gezilerinde bulunmuştur. Yozgat'ta ciddi bir öğrenme arzusu fark eden Amos, uygun ve güvenilir birinin bulunmamasından dolayı 1854 yılında bu yörede istasyon açamamıştır (Farnsworth, 2018, s.57-58). 
Wilson Amos'un 1863 yılındaki notlarından anlaşıldığı üzere Yozgat'ta bir kız okulu kurduğu anlaşılmaktadır. Yozgat'taki eğitim faaliyetlerine dair Wilson Amos; Geçen yıl olduğu gibi bu yıl da birkaç ay Yozgat'ta kaldık. Şu an en iyi elemanımız olan Kayserili Dr. Nahan Tutkalcıyan(?), eskiden birkaç yıl Yozgat'ta öğretmenlik yapmıştı, şimdi onun görevini Bay Derderyan üstlendi... Bu yıl, geçmişte hiç olmadığ kadar, hatta sonraki bazı yıllardan bile daha fazla eğitime hizmet ettik. Yaklaşık 30 kişi olan Yozgat'taki okulun öğrenci sayısı, Bay Derderyan yönetiminde 100 kişiye ulaştı... sözleri ile bilgi vermektedir (Farnsworth, 2018, s.71).

Wilson Amos'un 1862 yılında genel olarak eğitim çalışmaları hakkında verdiği bilgiler ise şu şekildedir; Okullarımızın bütünündeki öğrenci sayısı geçen yıl 123'tü, bu yıl 251 kişiye çıktı ve Protestan olduğu bildirilenlerin sayısı da 380'den 479'a yükseldi. Kitap satışı hâsılatının 4.800 kuruşa çıktı̆̆ını rapor edebilmiş olmak da bize güç verdi. Bu döneme ait istatistik tablo da, 12 vaiz ve yardımcı elaman ile dört öğretmenden ibaret bir yerli ekip oluştuğunu gösteriyor. Yine bu dönemde halk vaizlere ve öğretmenlere ayda yaklaşık 1.000 kuruş maaş desteği verdi. (Farnsworth, 2018, s.71).

Kayseri İstasyonu'ndaki eğitim hususunda öne çıkan üç okul vardır: Talas'taki Amerikan kız ve erkek kolejleri ile Kayseri'deki açılan anaokuludur (Demir, 2012, s. 1407). Kayseri İstasyonu'ndaki eğitim için yapılan girişimler vardır. Wilson Amos bu anlamda Kayseri İstasyonu'nda bir okul açmak için çabalarda bulunmuştur. Fakat bu kolay olmamıştır. Yaşanan sıkıntı ve zorluklara rağmen öncelikli olarak Kayseri yöresinde 1873 yılında bir kız okulu açılmıştır (Farnsworth, 2018, s.98).

Okulun kuruluşuyla ilgili olarak Amos; Eskisinden daha iyi bir mekân temin edemeseydik, Talas'ta bahis konusu bu kaliteli kız lisesini açamazdik. Fakat bu yıl çok güzel bir okul binası ve şapel inşa ettik, bunun hem okul mensupları hem cemaat üzerinde mükemmel tesiri oldu... ifadelerine kayıtlarında yer vermiştir (Farnsworth, 2018, s. 99). Talas'taki kız okulunun açılmasında Miss Sarah Closson ve Miss Ardele Griswor'un çabaları etkili olmuştur. Okul ilk zamanlarda insanların tepkilerine neden olmuş; fakat bu tepkilere rağmen öğrencilerden para alınmamak suretiyle birkaç kız öğrencinin bu okula gelmesi için ikna edilmelerinden sonra akabinde eğitime başlanmıştır. Yatılı olarak açılan okula ilk yıl yatılı kısmına iki kız öğrenci kayıt yaptırmıştır. Kayseri İstasyonu'ndaki birçok okulda olduğu gibi Amerikan Board misyoner yönetimindeki bu 
okullardaki Ermeni ve Rum öğrenciler için ortak dil olarak Türkçe kullanılmıştır (Demir, 2012, s.1408-1409).

Talas Amerikan Kız Koleji'nde okutulan derslere bakılacak olursa; Aritmetik, Coğrafya, Ermenice Gramer ve Tercüme, Rumca Gramer, Alfabe, Osmanlıca Gramer olup bunların yanı sıra Psikoloji Eğitimi, Vokal ve enstrümantal müzik derslerinin müfredatta yer aldığı Amerikan Board belgelerinde görülmektedir. 1894 yılından itibaren de düzenli bir şekilde İngilizce dersleri verilmeye başlanmıştır. Bu sayede İngilizce yeni başlayanlar için zorunlu hale getirilmiştir (Demir, 2012, s.1409).

Talas Amerikan Kız Koleji'nde okuyan kızlar ders zamanlarının dışında, kadınlar için düzenlenen dua toplantılarına katılmaktadır. Düzenli bir şekilde İncil eğitimi almakta ve ev ziyaretlerinde bulunarak buralardaki kadınlara İncil öğretmektedirler. Bu sayede bölgedeki insanlara nüfuz ederek onların güvenleri kazanılmaktadır. Böylelikle Amerikan Board birliğinin hedefleri ve misyonerlik çalışmaları yerine getirilmiştir (Demir, 2012, s.1409).

1881 yılında hem Talas Kız Yatılı Okulu için büyük bir bina hem de misyoner ailelerden birinin oturması için bir ev inşa etmek maksadıyla aşağı Talas'ta bir arsa satın alınmıştır. Arsanın ruhsat alımında birtakım sıkıntılar yaşanmıştır. Bu girişimler devam ederken eğitim faaliyetlerine ara verilmemiştir. 1889 yılında Wilson Amos, Talaslı Rumların kızlarını okula verdiğini ve eğitime olan ilginin arttığını belirtmektedir. Ayrıca 1889 yılının sonbaharında Amerikan Board Teşkilatı, Talas'ta ilk anaokulunu açmıştır. Anaokulunun kuruluşuna dair bilgileri veren Wilson Amos; Bu yılın sonbaharında, Talas'ta ilk anaokulumuz açldr. Bayan Bartlett tarafindan İzmir'deki anaokulu bölümünde çok iyi bir eğitim almış olan Kayserili Bekâr Bayan Gulhar(?) Kılıçyan öğretmen oldu. Bu okul özel bir girişim olarak açıldı ve Board'dan herhangi bir para desteği talep edilmedi. ifadelerini kullanmıştır (Farnsworth, 2018, s.17-176).

Geçen zaman içerisinde Talas Kız Okulu ilk mezunlarını 1883 yılının Eylül ayında vermiştir. 1883 Mart ayında ise okul dört yıllık düzenli bir eğitim programı uygulamayı benimsemiştir. Mezun sayısıyla ilgili ve işleyen süreçle alakalı olarak Wilson Amos; Bu yılın eylülünde de ilk mezununu verdi. Altı kişi mezun oldu. Hepsi Protestan cemaatine mensuptu. Mezun olduktan sonra "hepsi de kadınlar arasında öğretmenlik yapmak ve dini faaliyet göstermek üzere kendilerine uygun önemli görevler buldu." Yal içinde 
bu kurumun 10'u gündüzlü olmak üzere 58 öğrencisi vardı. Bunların sekizi cemaate intisap etti. Böylece cemaate mensup öğrencilerin sayısı 27 oldu. Bunların yaşı ortalama 16 civarındaydı. bilgilerini vermektedir (Farnsworth, 2018, s.151).

1893 yılında Talas Kız Yatılı Okulu 6. dönem mezunlarını vermiştir. Okul altısı Ermeni, dördü Rum olmak üzere on yedi kişiyi daha mezun etmiştir. Gün geçtikçe okulun mezun sayısı artmaktadır (Farnsworth, 2018, s. 198). Wilson Amos'un kayıtları bunu desteklemektedir. Belirttiği üzere 1899 yılına gelindiğinde okulun toplam mezun sayısı 83'e ulaşmıştır (Farnsworth, 2018, s.234).

Kız kolejinin ardından Talas'ta erkek koleji kurulmuştur. Yapılan girişimler sonucunda Amerikan Erkek Koleji 1883 yılının güzünde açılmıştır. Okula öğretmen olarak Kayseri Pastörü Kerope Yakubuyan'ın oğlu ve Antep Koleji mezunu olan Haygazun Yakubuyan atanmıştır (Farnsworth, 2018, s. 150). Talas Amerikan Erkek Koleji ilk ve orta derecede eğitim ve öğretimin yapıldığı bir okuldur (Demir, 2012, s.1411). Talas Amerikan Erkek Koleji'nin orta dereceli kısmında verilen eğitim yedi yıldır. Yedi yıllık sürede öğrencilere verilmekte olan dersler; İngilizce, Ermenice, Rumca, Türkçe, Fransızca, Aritmetik, Temel Muhasebe, Cebir, Geometri, Fizik, Botanik, Zooloji, Coğrafya, Tarih, Trigonometri, Yüksek Cebir ve Güzel Konuşma Sanatıdır. Bu seçmeli ders uygulaması ise liseden sonra yüksekokul düzeyinde eğitimlerini sürdürmek isteyen öğrenciler için uygulanmaktadır (Demir, 2012, s.1412).

Talas Amerikan Erkek Koleji'nden mezun olan öğrenciler, eğitimlerine devam etmek istemeleri veya yeterli donanıma sahip olmaları durumunda bir üst eğitim kurumu olan yüksekokullarda eğitimlerine devam etmişlerdir. Talas Amerikan Kız ve Erkek Koleji'nden mezun olan öğrenciler, liseyi bitirdikten sonra geldikleri yörelerde ya da Amerikan Board tarafından atandıkları okullarda öğretmenlik yapabilmekteydi. Başka bir seçenek olarak da mezun öğrenciler ticaretle uğraşarak hayatlarını idame ettirebiliyorlardı. Buna istinaden öğrencilerin ticaretle uğraşmayı tercih edebilecekleri düşüncesiyle lise eğitimleri boyunca bu yönde de eğitimler verilmiştir (Demir, 2012, s.1414). 1903 yılına gelindiğinde ise Wilson Amos eğitim seviyesinin yükseltilmiş olmasından dolayı erkek okulun- 
dan o yıl kimsenin mezun olamadığını kaydetmiştir (Farnsworth, 2018, s.256).

Wilson Amos, çektiği zorluklara rağmen Kayseri İstasyon'unda belirlenen hedeflerin birçoğunu gerçekleştirmiştir. Sayısız keşif gezilerinde bulunmuştur. Ancak yaşının ilerlemesi sonrası dolayısıyla keşif gezilerine çıamaz olmuştur. Elli yılını Kayseri'de geçirmiş olan Wilson Amos Farnsworth, eşi ile beraber 14 Eylül 1903 tarihinde yurt edinmiş olduğu yöreden ayrılmıştır (Farnsworth, 2018, s. 262). Kayseri'ye dair tutmuş olduğu notlara 1870 yılında arkadaşlarının ısrarı ile başlamıştır. Akabinde bu notlarına 1904 yılında son vermiştir. Kapadokya'daki faaliyetler hakkında herkesin ilgisini çekecek pek çok malzeme bulunacağına inandığını satırlarında yer vermiştir (Farnsworth, 2018, s.263-264).

\section{Sonuç}

Eğitim, toplumların geleceğini teminat altına alma noktasında önemli bir unsurdur. Toplumlar gelişimini ve ilerleyişini bu önemli olgu sayesinde sağlamaktadır. Osmanlı'nın 19. ve 20. yüzyılda kendini keşfetmeye çalışması bu hususta bir boşluk meydana getirmiştir. Amerikan Board Teşkilatı, Osmanlı'nın kendini arayış dönemini fırsata çevirmiş ve bu boşluktan istifade etmiştir. Eğitimin önemini kavramış olan Amerikan Board bu etkeni kullanarak misyonerlik faaliyetleri için önemli bir araç olarak kullanmıştır.

Amerikan Board, Batı Türkiye Misyonu kapsamında Kayseri'de bir üs kurmuştur. Kayseri İstasyonu'nda dini faaliyet amacıyla başlamış olan misyonerlik çalışmaları yerini eğitim alanındaki girişimlere bırakmıştır. Birliğin görünürdeki amacını dini faaliyetler oluşturmaktadır; ancak gizli tutulan amaç ise ekonomik, siyasi, askeri ve kültüreldir. Wilson Amos Farnsworth da bu kapsamda ilk olarak cemaat kurma, matbaa, okul ve hastane açma girişimlerinde bulunmuştur. Misyonerlik faaliyetlerini bu eksenler etrafında yürütmüştür. "Neden Kayseri bölgesi?" denilecek olursa burada gayrimüslim tebaanın nüfusu dikkate alınmış, gayrimüslim tebaanın çoğunlukta olması misyonerlik faaliyetleri için en uygun alanı oluşturmuştur.

Bu bağlamda Wilson Amos, yaşadığı yöreye daha önce bilmedikleri yenilikleri tanıtmada da öncüllük etmiştir. Halkın dilini öğrenerek, on- 
ların kültürlerine hâkim olmak suretiyle yörenin insanlarıyla bir bağ kurmuştur. Bu sayede Wilson Amos, Amerikan kültür ve yaşam tarzını halka tanıtmıştır. Wilson Amos aynı zamanda bu yaşam tarzını bölge insanına zorlayarak değil sevdirerek yaymıştır. Misyonerliğin dini misyonunun yanında iki önemli hedefi vardır. İlkini sağllk, ikincisini ise eğitim oluşturmaktadır. Belirlenen bu hedefler ise azınlıklara yönelik kullanılmıştır. Onların eğitilmesine önem verilmiştir.

Kayseri İstasyonu, Amerikan Board'un en etkili olduğu yer olmuştur. Wilson Amos bu konuda çokça emek ve çaba sarf etmiştir. Kurulmasında öncü olduğu Talas Kız ve Erkek Kolejleri sayesinde yeni elemanlar yetiştirilmiştir. Buradan mezun olan öğrencileri Ankara, Nevşehir ve Niğde gibi bölgelere göndererek, misyonlarının yayılmasında araç olarak kullanmışlardır. Eğitim alan öğrenciler boş zamanlarında toplumla yakınlaşarak, Batı Türkiye Misyonu'nun yayılması için faaliyetlerde bulunmuşlardır. Wilson Amos eğitimin önemini iyi kavramış olacak ki okul kurmanın yanı sıra kitap çıkarmak için de çaba sarf etmiştir. Daha çok kitle edinebilmek adına eğitimle alakalı olarak her detay tek tek değerlendirilmiştir.

Wilson Amos Farnsworth, elli yıl boyunca hayatını misyonerlik gayelerini gerçekleştirmek için Kayseri yöresinde geçirmiştir. Süreç içerisinde yaşanan birtakım sıkıntı ve zorluklara rağmen hedeflerinden sapmamıştır. Amerikan Board'un kendisini gönderirken belirlediği amaçları gerçekleştirmede aşırı gayrette bulunmuş; bu hususta ne denli başarılı olmuştur düşündürücüdür. Halkın Müslüman olması ve belli bir örf ve âdetle yetişmiş olmaları Wilson Amos için güç bir durum olmuştur. Çünkü bu tarz insanları etkilemek ve inançlarını bir anda değiştirmek kolay değildi. Elli yıllık süre zarfında elbette faaliyetlerini gerçekleştirirken tepki çekmiştir; fakat bu yıldırıcı bir sebep olmamıştır.

Misyonerlik faaliyetleri bir nevi Osmanlı Devleti'nin hükmettiği topraklarda nüfuz alanı oluşturmayı hedeflemektedir. Yapılan eğitimsel ve kültürel girişimler, bu amacın gerçekleştirilebilmesi noktasında kültürel bir ticarettir. Wilson Amos bu kapsamda, Kayseri yöresi başta olmak üzere yeni dış istasyonlar da kurabilmek için keşif gezilerinde bulunmuştur. Üs kurmak için girişimler sürekli bir şekilde devam etmiştir. Yozgat dâhil olmak üzere birçok ilde üs kurmuşlardır. Fakat faaliyet ve 
etkilerinin bir süre sonra kendi içlerinde oluşan boşluk ve istikrarsızlıklardan dolayı zayıfladığı görülmektedir.

Sonuç olarak belirtmek gerekir ki Osmanlı Devleti'nin içinde bulunmuş olduğu modernleşme çabaları misyonerler için bir umut teşkil etmiştir. Osmanlı topraklarını faaliyetlerini gerçekleştirmek adına kullanma yoluna gitmişlerdir. Anlaşılmaktadır ki dönemin sosyoekonomik ve sosyo-kültürel anlamda nabzının tutulmasında misyonerler bir şekilde etkili olmuşlardır.

"Misyonerlik bir araç mıdır; yoksa bir amaç mıdır?" sorusu akıllara gelmektedir. Bu da ayrıca bir tartışma konusudur. Bu çalışmamızda, Osmanlı'nın 19.yüzyılda eğitim anlamında oluşan boşluklarının yabancı misyonerler tarafından nasıl doldurulduğu irdelenmeye çalışılmıştır. 


\title{
EXTENDED ABSTRACT \\ An Educator on a Mission in Ottoman Lands in the 19th Century: Wilson Amos Farnsworth's Cappadocia Activities
}

\author{
Ercan Kaçmaz - Büşra Figenkaplan \\ Hacı Bektaş Veli University
}

19th century and 20th century were periods when the Ottoman state was open to change. In the men-tioned periods, the government wanted to increase the power of the state by the state administration as well as the civil organizations such as civilian and military schools, chambers of commerce, sects, and finally by taking control of madrasahs, which are the best representatives of religious education, and by shaping them in line with their own mentality and ideology. However, these reforms, which the government wanted to carry out, lacked much infrastructure due to war, political instability and economic fluctuations, and the situation was not stable.

In the 19th and 20th centuries, almost every day, new laws emerged within the Ottoman state structure, and one was engaged in the other without getting used to. The minister of education, who spent more than a year in office, seemed almost absent. Even this situation is quite striking to show how volatile, fluctuating and unstable the period is. When the system changed, it was inevitable for the institutions to change. In the West, because the modernization took place without radical system changes, the institutions of the old system could easily be reformed. Ottoman modernization began against tradition. This situation has made the Ottoman lands an area where missionary educators can easily carry out their activities. One of them was Wilson Amos Farnsworth. Farnsworth turned this chance into an opportunity by the American Board to carry out its activities from one end of the world to the other end of the Cappadocia region. This study will focus on of how the gaps in the educational sense of the period are tried to be filled by foreign missionaries.

In the 19th century, when the Ottoman State entered into a change and transformation within itself, weaknesses occurred in certain circles 
of the system. Especially the shocks experienced in the field of education were totally within the vision of the missionaries. By means of this opportunity, they tried to gain influence in the Ottoman society and in the state structure. Noticing this situation of the Ottoman Empire, the American Board Organization attempted to fill this gap. This study ephasizes the changes and effects of the missionary activities of the Cappadocia region with the changes in the state structure and the process of modernization.

When we look at the modernization of the Ottoman Empire in the field of education, it is seen that it continued until the end of the state starting from the end of the 1700s. In the Ottoman Empire, the westernization and modernization movements were mostly in military, political administrative areas and a few were in social ones. This change started and continued in the institutions where the sultan and the grand vizier had a direct effect (Karataş, 2003, p.232).

When the system changed, it was inevitable to change the institutions. Since modernization in the West took place without radical system changes, the institutions of the old system could easily be reformed. Ottoman modernization began against the tradition (Sarıkaya, 1997, s.200). This situation made the Ottoman lands an area where missionary educators could easily carry out their activities. One of these missionaries was Wilson Amos Farnsworth. Farnsworth came to the Cappadocia region to carry out the missionary activities from one end of the world to the other end, through the American Board Organization, which sought to turn this state of the Ottoman Empire into an opportunity.

Wilson Amos Farnsworth and Jasper Newton Ball were sent directly by the American Board to appoint a missionary station covering the Cappadocia region. Both missionaries stayed in this region together with their spouses (Farnsworth, 2018, p.36).

It is understood from the notes of Wilson Amos that he founded a school for girls in Yozgat in 1863. Wilson Amos informs on educational activities in Yozgat thus; We stayed in Yozgat for a few months this year as it was last year. Now our best employee, Kayserili Dr. Nahan Tutkalctyan (?) had formerly taught in Yozgat for a number of years, and now Mr Derderyan has taken on his duties... This year, we have served even more years of education than ever, even some of the later years. The number of students in the school in 
Yozgat, which is about 30, has reached 100 people under the direction of Mr. Derderyan (Farnsworth, 2018, p.71).

In spite of the difficulties, Wilson Amos reached many of the targets set at Kayseri Station. He was involved in countless exploration trips. However, after the advance of his age, he could not go on exploration trips. Wilson Amos Farnsworth, who spent fifty years in Kayseri, left his second home on 14 September 1903 with his wife (Farnsworth, 2018, p. 262). In this context, Wilson Amos pioneered in introducing innovations that they did not know before. By learning the language of the people, he established a connection with the people of the region by knowing their cultures. In this way, Wilson Amos introduced the American culture and lifestyle to the people. Wilson Amos also spread this lifestyle devotedly, not forcing the people of the region. The missionary had two important goals besides the religious mission. The first one was health and the second one was education. These golas were used for minorities. Their education was given importance.

As a result it should be noted that the modernization efforts of the Ottoman Empire were a hope for the missionaries. They used the Ottoman lands in order to carry out their activities. It is understood that in terms of the socio-economic and socio-cultural sense of the period, the missionaries were somehow effective. Is missionary a means; or is it a goal? is the main question that comes to minds. This question has also been a matter of discussion. Thus, this study has examined how the gaps in Ottoman education in the 19th century were filled by foreign missionaries.

\section{Kaynakça / References}

Akyüz, Y. (2011). Osmanlı döneminden cumhuriyete geçilirken eğitimöğretim alanında yaşanan dönüşümler. Pegem Eğitim ve Öğretim Dergisi, 1 (2), 9-22.

Alkan, M. Ö. (2008). Osmanlı İmparatorluğu'nda modernleşme ve eğitim. Türkiye Araştırmaları Literatür Dergisi, 6 (12), 9-84.

Anderson, R, (1872). History of the missions of the American board of commissioners for foreign missions to the oriental churches. Vol. I. Boston: Congregational Publishing Society. 
Bozaslan, B. M. ve Çokoğulları, E. (2015). Osmanlı'dan cumhuriyet'e modern eğitimin inşası: Devletin kurtarılmasından devletin kurulmasına. Gazi Üniversitesi İktisadi ve İdari Bilimler Fakültesi Dergisi, 7 (3), 309-329.

Brigette C. K. (2011). Finding Aid for American Board of Commissioners for Foreign Missions Records, Section 12, Missionary Research Library Archives, 1878-1958. Accessed on the 3rd of March 2019 from

https://library.columbia.edu/content/dam/libraryweb/locations/b urke/fa/mrl/ldpd_4492650.pdf

Cebeci, D. (2009). Tanzimat ve Türk ailesi. İstanbul: Bilge Oğuz Yayınları.

Demir, C. (2008). Kayseri, Nevşehir, Niğde üçgeninde Amerikan board'un eğitim faaliyetleri, YayımlanmamışYüksek Lisans Tezi,. Erciyes Üniversitesi, Sosyal Bilimler Enstitüsü, Tarih Anabilim Dalı, Kayseri.

Demir, C. (2012). Amerikan Board belgelerine göre Talas Amerikan kız ve erkek kolejleri. Turkish Studies, 7 (4), 1405-1420.

Döşkaya, F. Ç. (2018). Amerikan Board ve Misyoner Corinna Shattuck'in Urfa faaliyetleri. Akademik Tarih ve Düşünce Dergisi, İlkbahar, 5(14), 84-119.

Duran, A. (2017). Meşrutiyet dönemi eğitimdeki yenileşme hareketleri ve cumhuriyet dönemine bıraktığı miras. Capadocia Journal Of History And Social Sciences, 8, 62-77.

Emecen, M. F. (2016). Osmanlı İmparatorluğu'nun kuruluş ve yükseliş tarihi:(1300-1600). İstanbul: Türkiye İş Bankası Kültür Yayınları.

Farnsworth, W. A. (2018). Kapadokya'daki Amerikal Misyonerlerin bilinmeyen tarihi:1853-1903. Mehmet Şahin (çev.). İstanbul: Yapı Kredi Yayınları.

Fidan, S., Şahin, K. ve Çelik, F. (2011). Osmanlı modernleşmesinin temel olgularından biri: Bürokrasi, Osmanlının modernleşmesinde bürokrasinin etkinliği ve önemi. Süleyman Demirel Üniversitesi Fen Edebiyat Fakültesi Sosyal Bilimler Dergisi, 23, 113-128.

Figenkaplan, B. (2018). Osmanlı Eyübü'nde kadın ve mülkiyet:1700-1725. Yayımlanmamış Yüksek Lisans Tezi,. Nevşehir Hacı Bektaş Veli Üniversitesi, Sosyal Bilimler Enstitüsü, Tarih Anabilim Dalı, Nevşehir. 
Greene, J. K. (1916). Leavening the levant. Boston, New York, Chicago: The Pilgrim Press.

Karabulut, M. (2016). Osmanlı İmparatorluğu'nda 19. yüzyılda değişim süreci, sosyal ve kültürel durum. Mecmua Uluslar Arası Sosyal Bilimler Dergisi, 1(2), 49-65.

Karagöz, M. (1995). Osmanlı Devletinde 1slahat hareketleri ve batı medeniyetine giriş gayretleri:1700-1839. Ankara Üniversitesi Osmanl Tarihi Araştırma ve Uygulama Merkezi Dergisi, 6, 173-194.

Karal, E. Z. (2011). Osmanl Tarihi Islahat Ferman devri:1861-1876, Cilt VII, Ankara: Türk Tarih Kurumu Basımevi.

Karataş, S. (2003). Osmanlı eğitim sisteminde batılılaşma. Afyon Kocatepe Üniversitesi Sosyal Bilimler Dergisi, 5 (1), 231-241.

Karpat, H. K. (2014). Osmanlı modernleşmesi toplum, kuramsal değişim ve nüfus, (C. Elitez çev.). İstanbul: Timaş Yayınları.

Kodaman, B. (2005). Osmanlı'dan cumhuriyet'e çağdaşlaşma sorunları. Selçuk Üniversitesi Türkiyat Araştırmaları Dergisi,18, 149-158.

Pardoe, J. (1837). The city of the sultan and domestic manners of the Turks in 1836. London: Henry Colburn Publisher Company.

Richter, J. (1910). A History of Protestant Missions in The Near East. Edinburgh: Oliphant, Anderson \& Ferrier.

Sarıkaya, Y. (1997). Medreseler ve modernleşme. İstanbul: İz Yayıncılık.

Soydan, T. ve Tüncel, M. (2013). Osmanlı'da ilk yenileşme döneminde eğitimin kurumsal ve yönetsel yapısının oluşumu ve gelişimi. Milli Eğitim Dergisi, 42, 110-126.

Strong, W. E. (1910). The story of the American Board. Boston: The Pilgrim Press.

\section{Kaynakça Bilgisi / Citation Information}

Kaçmaz, E. ve Figenkaplan, B. (2019). 19. Yüzyılda Osmanlı topraklarında eğitimci bir misyoner: Wilson Amos Farnsworth'un Kapadokya faaliyetleri. OPUS-Uluslararası Toplum Araştırmaları Dergisi, 11(18), 2776-2796. DOI: 10.26466/opus.560699 